\title{
二元羧酸经咪唑啉还原为二醛的 新合成方法研究
}

\author{
史 真 顾 焕、许莉莉 \\ (西北大学化学系, 西安 710069)
}

\section{关镜词 二元䍪酸 咪唑啉 二醛 新合成法}

二醛是重要的有机化工原料, 在纺织品、医药、染料、粘合剂、涂料等方面有广泛的用途, 二

性不变. 因此如果反应物(产物)的所有占据分子轨道(非占据分子轨道)按对称性都只与产物 (反应物) 的占据分子轨道 (非占据分子轨道) 相关联, 那么意味着, 反应的活化能不大, 不需要 光激发, 只在通常加热的情况下, 反应就能进行, 即可以从反应物的基态到产物的基态. 反之, 若反应物 (产物) 的占据轨道 (非占据轨道) 按对称性与产物 (反应物) 的非占据轨道 (占据轨道) 相关联, 那么反应的活化能较大, 在通常加热情况下, 反应不能进行, 必须通过光照方法, 使反 应物激发, 即某些占据轨道的电子激发到一定的非占据轨道上去, 这样, 在化学反应时, 按轨道 对称性守恒的要求, 由反应物的激发态到产物的基态才是可能的. 因此, 图 2 说明由 $\mathrm{N}_{6}$ 分子 去合成 $N_{12}$ 分子时, 在加热情况下完成该反应是很困难的, 但如果在光照激发作用下, 由 $N_{6}$ 分 子生成 $N_{12}$ 分子或许是可行的.

致谢本工作为国家自然科学基金(批准号:29290302)、国家教育委员会博士点基金(批准号: 9218305) 资助项目.

\section{参考 文 献}

1 Vogler A, Wright R E, Kunkely H. Photochemical reductive cis-elimination in cisdiazidobis (triphenylphosphane) platinum ( II ) evidence of the formation of bis (triphenylphosphane) platinum (0) and hexaazabenzene. Angew Chem, Int Ed Engl, 1980, 19: 717

2 Engelke R. Five stable points on the $\mathrm{N}_{6}$ energy hypersurface: structures, energies, frequencies, and chemical shifts. J Phys Chem, 1989, 93: $5722 \sim 5727$

3 Engelke R, Stine J R. Is $N_{8}$ cubane stable? J Phys Chem, 1990, 94: $5689 \sim 5694$

4 Lauderdale W J, Stanton J F, Bartlett R J. Stablity and energetics of metastable molecules: tetraazatetrahedrane $\left(\mathrm{N}_{4}\right)$, hexaazabenzene $\left(\mathrm{N}_{6}\right)$, and octaazcubane $\left(\mathrm{N}_{8}\right)$. J Phys Chem, 1992, 96: $1173 \sim 1178$

5 Chen C, Lu L-H, Yang Y-W. Theoretical study of $\mathrm{N}_{20}$ using semiempirical molecular orbital methods. J Mol Struct, 1992, 253: $1 \sim 8$

6 Bliznyuk A A, Shen M, Schaefer III H F. The dodecahedral $\mathrm{N}_{20}$ molecule: some theoretical predictions. Chem Phys Lett, 1992, 198: $249 \sim 252$

7 Leininger $\mathrm{M} \mathrm{L}$, Sherrill C D, Schaefer III HF. $\mathrm{N}_{8}$ : a structure analogous to pentalene, and other high energy density minima. J Phys Chem, 1995, 99: 2 324 2 328

8 李前树, 曲 红, 朱鹤孙. 氮笼 $N_{10}$ 的量子化学计算研究. 科学通报, 1996, 41(6): 515 518

(1996-02-09 收稿, 1996-05-24 收修改稿) 
醛的传统生产法是二元醇的催化氧化法. 本文作者曾报道了咪唑啉在 $\mathrm{NaBH}_{4}$ 作用下的还原 开环反应 ${ }^{[1,2]}$, 本文研究咪唑啉在金属钠和乙醇作用下的还原反应, 提出了一种未见文献报道 的二元羧酸经咪唑啉中间体制备二醛的合成方法. 这一新合成法突破了二醛由二元醇催化氧 化制备的传统方法, 用来源丰富的二元羧酸作原料, 为二醛提供了一种新的简便的合成方法, 合成路线如下:

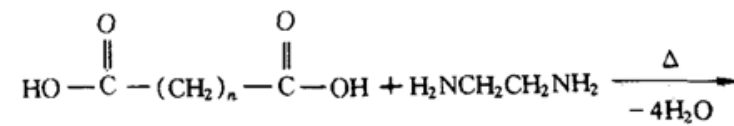
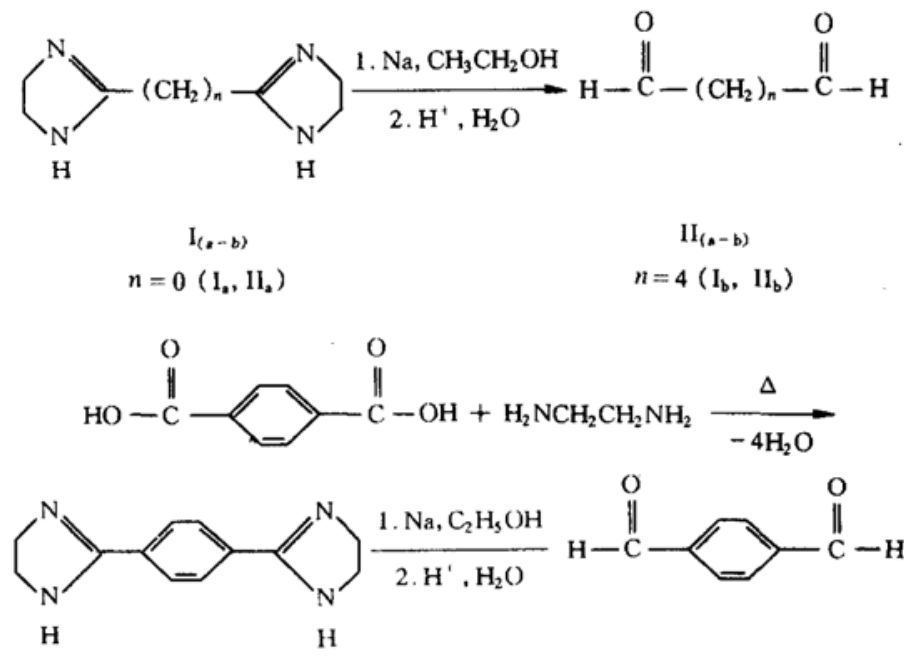

III

IV

反应中首先是羧酸与乙二胺脱水生成二咪唑啉, 接着还原、水解得到相应的二醛. 羧酸与 乙二胺生成味唑啉的反应已有报道 ${ }^{[3]}$, 味唑啉在金属钠和乙醇作用下的还原水解反应未见文 献报道, 羧酸经咪唑啉还原为醛的合成方法也未见文献报道. 本文通过这一新合成法, 分别合 成了乙二醛、已二醛和对苯二醛,并对这一新合成法中反应条件对二醛收率的影响作了研究和 讨论.

\section{1 实验}

\section{1 仪器与试剂}

2-WA-J 阿贝折射仪; X4 型显微熔点测定仪, 温度计未经校正;试剂均为化学纯.

\section{2 二咪唑啉 $\left(I_{(a-b)} 、 I I\right)$ 的合成}

参照文献[3]合成. 化合物 $\mathrm{I}_{\mathrm{a}}$ : 白色固体, 收率 $86.3 \%, \mathrm{~m}$. p. $290^{\circ} \mathrm{C}$ (文献值 ${ }^{[4]}: 289 \sim$ $291^{\circ} \mathrm{C}$ ) ; $\mathrm{I}_{\mathrm{b}}$ : 白色固体, 收率 $88.4 \%, \mathrm{~m}$. p. $218 \sim 219^{\circ} \mathrm{C}$ (文献值 ${ }^{[5]}: 218.5 \sim 219{ }^{\circ} \mathrm{C}$ ); III : 白色固 体, 收率 $80.4 \%$, m. p. $316 \sim 318^{\circ} \mathrm{C}$ (文献值 ${ }^{[6]}: 318^{\circ} \mathrm{C}$ ).

\section{3 二酫 $(\mathbb{I}(a-b) 、 N)$ 的合成}

三颈瓶中加入 $50 \mathrm{~mL}$ 无水乙醇, 溶入 $0.05 \mathrm{~mol}$ 二咪唑啉, 维持溶液温度在 $-5^{\circ} \mathrm{C}$ 以下, 搅 拌并氮气保护下, 加入 $0.25 \mathrm{~mol}$ 表面光洁无氧化层的金属钠片, 钠片加入速度以维持溶液温 度不超过 $-5^{\circ} \mathrm{C}$ 为宜, 待钠溶完后 (约连续摚拌 $30 \sim 45 \mathrm{~min}$ ), 静置片刻, 边搅拌边滴加 $50.4 \mathrm{~g}$ 
$(0.4 \mathrm{~mol})$ 水合草酸的 $80 \mathrm{~mL}$ 水溶液, 滴加速度以维持溶液反应平稳为宜, 待草酸加完后, 回流 $1.5 \sim 2.0 \mathrm{~h}$. 化合物 $\mathrm{I}_{\mathrm{a}}$ 的制备 : 上述反应液回流结束后, 蒸馏收集液体部分于三颈瓶中, 置三 颈瓶于温水浴中, 滴加适量 2, 4-二硝基苯肼试剂, 搅拌反应 $0.5 \sim 1.0 \mathrm{~h}$, 蒸去溶剂, 固体用水 的乙醇溶液重结晶, 得橙黄色沉淀, 收率 $76.4 \%, \mathrm{~m} . \mathrm{p} .137 \sim 138^{\circ} \mathrm{C}$ (文献值 ${ }^{[7]}: 138 \sim 140^{\circ} \mathrm{C}$ ); 化合物 $I_{\mathrm{b}}$ 的制备: 上述反应液回流结束后, 蒸除乙醇, 乙醚萃取, 蒸馏收集 $92 \sim 94^{\circ} \mathrm{C} / 1.1999$ $\mathrm{kPa}$ 馏分, 收率 $79.1 \%, n_{\mathrm{D}}^{20} 1.4338$ (文献值 ${ }^{[8]}$ : b. p. $92 \sim 94^{\circ} \mathrm{C} / 1.1999 \mathrm{kPa}, n_{\mathrm{D}}^{20} 1.4350$ ); 化合 物 IV 的制备: 上述反应液回流结束后, 蒸除乙醇, 冷却、过滤, 固体用水重结晶, 得白色结晶, 收 率 $81.6 \%$, m.p. $114 \sim 115^{\circ} \mathrm{C}$ (文献值 ${ }^{[9]}: 114 \sim 116^{\circ} \mathrm{C}$ ).

\section{2 结果与讨论}

实验发现, 反应温度、金属钠和二咪唑啉的摩尔比、反应时间对二咪唑啉还原水解反应收 率均有影响, 以化合物 I (a) 在钠和乙醇作用下还原水解为乙二醛 II (a) 的反应做条件实验, 在反 应时间、金属钠与二咪唑啉的摩尔比相同的条件下, 随着反应温度的降低, 乙二醛的收率有明 显增加, 适当过量的金属钠可使收率增加, 当温度为 $-5 \sim-10^{\circ} \mathrm{C} 、$ 金属钠与二咪唑啉的摩尔比 为 5.0 、还原反应时间 30 45 min, 已得到较好产率的乙二醛 $(76.4 \%)$. 实验发现, 水解反应 的 $\mathrm{pH}$ 值对二醛的收率有一定影响, 实验中用草酸的水溶液水解, 结果表明, $\mathrm{pH}$ 值为 $3 \sim 2$ 时, 水解所用水合草酸摩尔量与二咪唑啉摩尔量之比为 $8 \sim 10$ 时, 可得到较好产率的二醛.

乙二醛(化合物 $I_{\mathrm{a}}$ )沸点低 $\left(50.4^{\mathrm{C}} \mathrm{C}\right.$ ), 化学性质很活泼, 与 2,4 -二硝基苯肼形成的苯腙容 易提纯和鉴定. 所以在制备乙二醛的实验中, 加入 2,4 -二硝基苯胖, 所得到的苯腙的熔点与 文献报道一致.

致谢 本工作为陕西省自然科学基金(批准号:FF95407)资助项目。

\section{参考文献}

1 史 真, 杨卫国、季铰盐型表面活性剂的合成及物化性能测定．高等学校化学学报, 1994, 15(7): $1013 \sim 1016$

2 史 真, 王东权, 范乃丽. 味坐㗎还原开环反应及其在有机合成中的应用研究. 西北大学学报 (自然科学版), 1994, 24 (5): $15 \sim 18$

3 史 真,李 娜. 烷基咪唑啉二䍪酸盐的合成. 西北大学学报(自然科学版), 1994,24(3)：219 221

4 Woodburn H M. The reaction of cyanogen with organic compounds. J Org Chem, 1952, 17(2): $1235 \sim 1244$

5 Oxley P. Amides, Part II . Preparation of 2-substituted 4, 5-dihydroglyoxalines and ring homologues from cyanides and alkylenediamines. J Chem Soc, 1947, 1: 497 505

6 Levesque G, Gressier J C. 4, 5-dihydroimidazoles from dithiocarboxylic esters, thiocarboxamides or nitriles. Synthesis, 1981, 10: $963 \sim 965$

7 Khusid A K, Chizhova N V. Regeneration of aldehydes from their bisulfite derivatives in water and organic solvents on ion-exchange resins. Zh Org Khim, 1985, 21(1): 43 52

8 Weast R C. Handbook of Chemistry and Physics, 63rd. Boca Raton, Florida: CRC Press Inc, 1982, C-81

9 北京化学试剂公司编. 化学试剂目录手册. 北京: 北京工业大学出版社, 1993.846 